\title{
INFORMATION AND ANALYTICAL SYSTEM FOR HAZARD LEVEL ASSESSMENT AND EMERGENCY RISK FORECASTING
}

\author{
Pavel V. Yemelin ${ }^{a}$, Sergey S. Kudryavtsev ${ }^{b, *}$, Natalya K. Yemelina $^{c}$ \\ ${ }^{a}$ Karaganda University of Economics Kazpotrebsoyuz, Department of Commodity Science and Certification, \\ Karaganda, Kazakhstan \\ ${ }^{b}$ Karaganda State Technical University, Mining Aerology and Occupational Safety Department, Karaganda, \\ Kazakhstan \\ ${ }^{c}$ Karaganda University of Economics Kazpotrebsoyuz, Department of Mathematics, Karaganda, Kazakhstan \\ * corresponding author: sk74_07@mail.ru
}

Abstract. The purpose of the article is to present an analytical system that allows users to process data necessary for an industrial risk analysis and management, to monitor the level of industrial safety in a given site, and to fulfil essential tasks within the field of occupational safety. This system's implementation will make the industrial safety management at industrial sites more effective. Multifactorial, probabilistic, determined models of accidents' hazard and severity indexes are integrated into the computing core of the Information and Analytical System. Then, statistical methods determine the risk assessment of occupational injuries and diseases.

The Information and Analytical System for Hazard Level Assessment and Forecasting Risk of Emergencies in the Republic of Kazakhstan allows users to work efficiently with large volumes of information and form a united analytical electronic report about the state of industrial safety. The main objective of the monitoring system is to conduct a comprehensive analysis and assessment of the state of accidents, traumas and occupational sickness rates at industrial sites, the results being classified by the degree of hazard and insalubrity of manufacture. The introduction of the computer monitoring system in the specialized services of the Emergency Management Committee and the Ministry of Investment and Development of the Republic of Kazakhstan, and at industrial enterprises throughout the country, will allow users to analyse the state of the industrial and occupational safety constantly and objectively; as a consequence, the implementation will go a long way towards comprehensively approaching the task of increasing safety levels at industrial sites.

KEYWORDS: Industrial safety, industrial traumatism, professional sickness rate, risk assessment, risk management, risk monitoring.

\section{INTRODUCTION}

As the international practice shows, the issues of monitoring hazard sources and forecasting the risk of natural and man-made disasters have a special value in the field of industrial safety. The assessment of material and financial resources, which is necessary for a localization and liquidation of disasters' consequences, depends on a reliable identification of hazard sources and the assessment of the territorial risk. Emergencies at industrial sites are associated with especially hard consequences, because not only people but also the environment are affected by the baneful influence of such disasters.

The current international normative base in the field of risk assessment and management is based on general principles and directives, which can only be offered as recommendations. These principles form ideas about the choice and application of systematic methods for risk assessment; however, they don't present any special criteria for the determination of the necessity of a risk analysis. Furthermore, they don't determine which type of a risk analysis is necessary for a specific application [1-7].

Modern requirements of the legislation of the Republic of Kazakhstan in the field of industrial safety, as a result of a harmonization with the international system of occupational safety standards, improve safety levels at industrial enterprises.

Currently, in the Republic of Kazakhstan, more and more attention is paid to the issue of improving safety control at industrial sites of various industries.

The sustained functioning of both separate manufacturing flows and an enterprise as a whole are top priorities for any management representative. To achieve these goals, enterprises often have special departments that are engaged in the development of measures and production controls aimed at reducing the risk of accidents while simultaneously improving safety and labour conditions.

As a rule, industrial safety management is characterized by the processing and analysing of a sufficiently large amount of information, on the basis of which the best managerial decisions can be made. Such information is required in order to increase the efficiency 
and reduce the decision-making time necessary to prevent accidents and traumatism at a given enterprise. The implementation of this system will allow services of occupational safety to process and systematize all incoming information about industrial subdivisions and the enterprise as a whole, analyse and manage industrial risks, and monitor the level of industrial safety within the enterprise. The effectiveness of measures for the prevention and elimination of man-made emergencies completely depends on the frequency, effectiveness and quality of the monitoring at the site.

The Ministry for Investment and Development (MID) of the Republic of Kazakhstan currently operates the Corporative Information and Communicative System of the State System for Prevention and Localization of Emergencies (CICS SSPLE). The aim of the CICS SSPLE is to provide information flow between departments and an analytical support of managerial decision-making based on: up-to-date methods of spatial analysis; modelling of the development of disasters; forecasting of catastrophic events; and liquidation of consequences while MID employees operate in facilities.

Because of CICS SSPLE's analysis of the required levels of monitoring for the state of potentially hazardous sites as well as SSPLE's assessment of potential emergencies, managerial decisions determining the prevention and liquidation of disasters have been significantly rising. These changes improve the quality of life in aspects of a civil protection, economics and the social sphere.

CICS SSPLE consists of 12 subsystems; chief among them is Supervisory Activities, which allows developers to automatize basic objectives of the State control in the field of the emergency management. It also provides the organization of information and interaction between departments falling under the MID of the Republic of Kazakhstan. Due to the implementation of an electronic Supervisory Activities subsystem, paper waste has been reduced and MID employees are now equipped with necessary program products for data registration and processing. Additionally, interested organizations and people now get an access to detailed information and analytical reports, as MID's State control oversees current procedures.

Operation of the Supervisory Activities subsystem is based on the decree known as the Information and Analytical System for Hazard Level Assessment and Forecasting Risk of Emergencies in the Republic of Kazakhstan, as developed by our research team.

\section{DeVEloped METhodology AND DISCUSSION}

The Information and Analytical System allows users to work efficiently with large volumes of information and form a united analytical electronic summary, which includes a brief description of industrial sites, information about general hazard levels, results of analysis and risk assessments of accidents, classes of accident risk, and data about the most dangerous "weak" spots of industrial sites from an industrial safety standpoint.

The system is based on the Guidelines for Risk Management on Hazardous Industrial Sites of the Republic of Kazakhstan ("The Guidelines"), developed by our staff and described earlier in great detail [8], and the Computer System for the Monitoring Hazard Rates of Industrial Enterprises in the Republic of Kazakhstan (CSM), which is able to collect, process, keep, exchange, and deliver information in the field of industrial safety as well as forecasting social and economic consequences of accidents.

The Guidelines and the CSM were tested and have received positive feedback from supervisory organizations of the Republic of Kazakhstan in the field of industrial safety (specifically the Paramilitary Emergency Rescue Service Komir, Emergency Management Department of Karaganda and East Kazakhstan regions), a research institute (the National Centre of Labor Hygiene and Occupational Diseases of the Ministry of Healthcare of the Republic of Kazakhstan), and a number of mining enterprises (the Coal Department of Arcelor Mittal Temirtau JSC, Kazakhmys Corporation LLP). These endorsements are reflected in articles and conference proceedings dedicated to the issues of accidents 9-12, work-related traumatism [13-15], and occupational sickness rates [16-19], as the systems are used to assess the hazard levels at industrial enterprises in the Republic of Kazakhstan 20 .

The Guidelines determine directions and methods for a complex assessment of the state of industrial and occupational safety. Furthermore, they serve as a methodological base for the development of preventative measures concerning disasters, accidents and casualties at hazardous industrial sites. The development of the Guidelines was based on current international and national standards in the field of risk management. They establish principles and general requirements for a risk analysis and assessment, as well as the determination of hazard rates at industrial enterprises. They also outline the future directions and methodological goals of research in industrial safety monitoring. Furthermore, multifactorial, probabilistic, determined models of accident hazard and severity indexes are integrated into the computing core of the expert system used in the Guidelines for accident risk assessment.

This system starts with a data collection. According to the Guidelines, organizations which run hazardous industrial sites should give specific data through the completion of subject-specific questionnaires. The questionnaires contain a list of criterial parameters, which allow enterprises to foretell the possibility of future accidents.

Enterprises send initial data for computing these criteria into regional Emergency Management Departments. Nowadays, there are about 17,000 industrial sites, divided into nine industrial fields, falling un- 
der the control of the MID's local subdivisions in the Republic of Kazakhstan. Earlier enterprises sent paper documents to the MID's local subdivisions in the Republic of Kazakhstan. This fact made the data processing a tremendous challenge, which was reflected by the quality and timeliness of the analysis and delivery of required information about industrial sites.

Multifactorial models allow users to assess the degree of accidental hazard risk via a plethora of criterial parameters comprising the base of judgements about the possibility of future incidents. These models allow users to compute quantitative risk values; what holds true for some industrial units will conceivably stand for the whole enterprise. These values are the base for the determination of hazard rates (and accident risks) of industrial enterprises. The application of a great number of criterial parameters of hazards is a new trend in this field. Filled questionnaires sent from enterprises are processed, and then mathematical models of indexes of accidents' hazards and severity are used for computing.

Figure 1 shows a scheme of the information stream used for the forming of the Republican database on common hazard levels of industrial enterprises.

All information within the system is kept in the united relational database on the server. Operators located in various geographically distant points (in regional Emergency Management Departments) and registered by general administrator and fill in the database.

Furthermore, the general operator can register users of the system, who have the exclusive right to go through the database (or a part of the database). These users (guests) could be employees of the customer, individuals, or legal entities who have purchased an access to the system.

Apart from basic data, the database keeps complete information about customer inquiries; that is, who modified the database (added, changed, or deleted data) or went through it, and when.

The general administrator of the system (or an administrator who he has registered with) appropriate rights of access, and administration manages access to the database and oversees the server. The administrator can add new users into the system and manages their rights of access while maintaining exclusive overarching rights over the system.

All the users of the system could be conventionally divided into 3 categories, such as administrators, operators and guests (Figure 2).

The structure of the Information and Analytical System consists of the following basic elements:

(1.) Module of registration and collection of data about hazardous industrial sites. It is the depository for supervisory objects and data for computing the levels and rates of hazards at industrial sites.

(2.) The computing module offers the possibility to transfer a massive amount of data for the determi- nation of hazard possibility rates and degrees from Emergency Management Departments functioning in regional areas, Astana, and Almaty into the Republican database of the Automatized Information and Managing System. It also makes a computation of the degree and rate of possible hazards at industrial sites.

(3.) The module of the information delivery provides graphic and tabular information about the levels and rates of hazards at industrial sites.

Input parameters for the Information and Analytical System are monitoring data, information about objects of supervision, data about what happened during previous emergencies, and the results of past supervisory inspections. Sources, which provide the system with data, are authorized organizations responsible for the supervision in the field of emergencies.

Output parameters for the Information and Analytical System are the information about registered objects of supervision, the results of inspections in the field of supervised activity and delivery of orders, and hazard rates and dynamics at industrial sites.

The architecture of the Information and Analytical System is the totality of databases, specialized software, which is interconnected in a distributed databank, and then united by the unified transport environment for an input, processing, search functions and the delivery of user-required information.

The structure of the information component of the system is conventionally divided into three layers:

\section{ANALYTICAL LAYER}

The functioning of analytical layer subsystems is based on a means of a multidimensional data analysis and other tools of analytic processing. Special mathematical methods should allow users to analyse and forecast the dynamics of changing rates and levels of industrial sites' hazards and form detailed reports on different schemes of delivery information users.

The extraction and transformation of data for a subsequent analysis by OLAP means should be fulfilled with the use of tools of data depositories, which include a subject-oriented, integrated, lasting, and stable data collection to inform managerial decisions.

\section{PROVIDING LAYER}

The providing layer is comprised of specialized software for a system administration and control of integrative processes between the system and information systems of other state organizations and legal entities.

The providing layer is a complex program made by the client-server architecture and consists of two basic program parts:

(1.) The server part, which is kept with the database in a unique copy on the server. Administratively, it is a united point of electronic collection/placing/processing for public information within the system. 


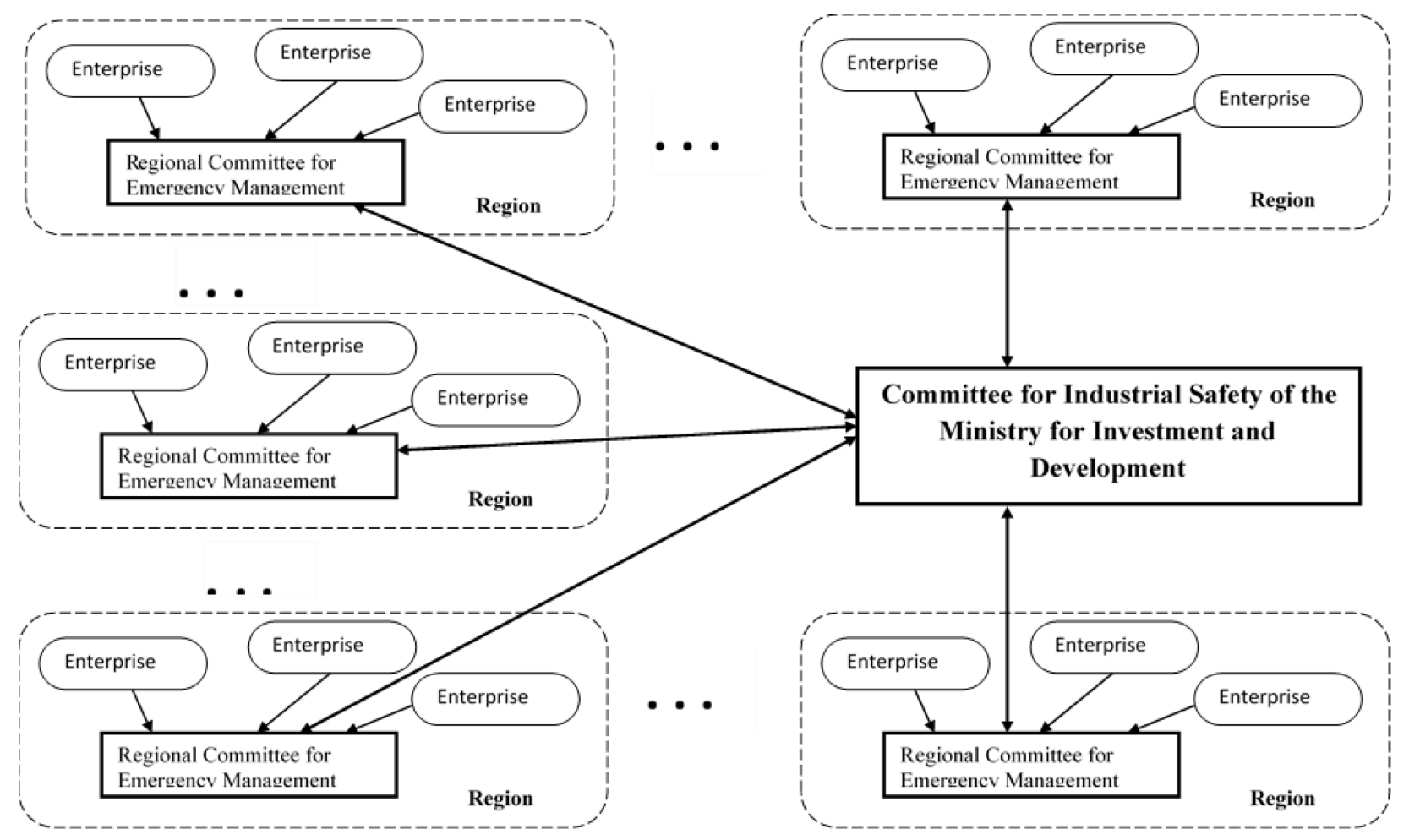

Figure 1. Chart of the formation of the Republican database on common hazard levels of industrial enterprises.

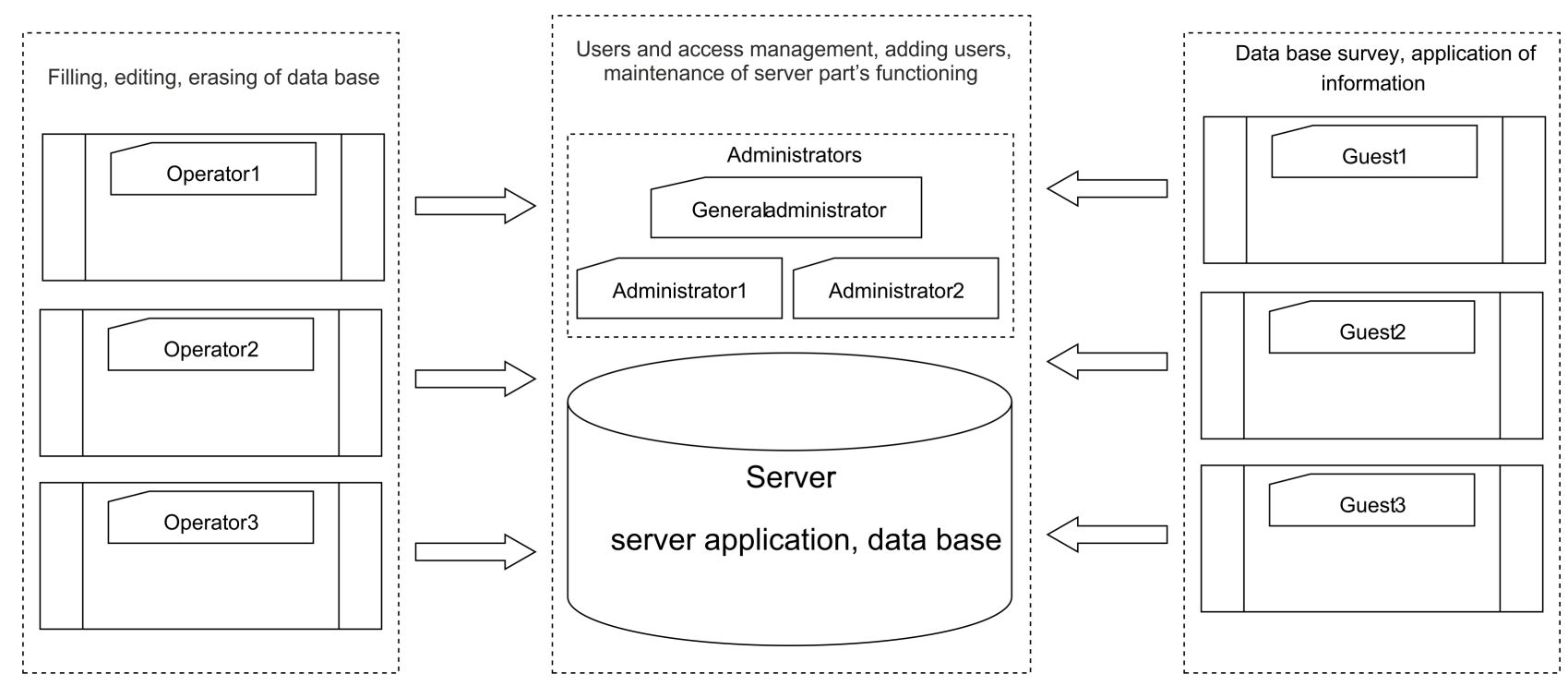

Figure 2. Scheme of system users, their information relations and functions. 
(2.) The client part is a web application that is opened in a web browser through a network connection (Internet or a local network) with the server. The transport protocol for the data transmission within a multiservice data network is TCP / IP.

Due to this form of the client application, there is no need to install any special software on the user side. The access to the client application manifests publicly as an ordinary web page, which will be kept on the main server.

The information interaction between different levels is assumed to move in a vertical direction.

Vertical information interaction is carried out through the "region-centre" chain from top to bottom and from the bottom up, and is used to transmit information about the operational situation from country regions to the centre as well as to transfer and bring information to concrete performers.

\section{OPERATING LAYER}

The operating layer unifies subsystems, which perform operational management of the processes of receipt and issuance of required structural and systematic information for reliable functioning and solving of tasks assigned to the Information and Analytical System in accordance with the requirements of management personnel

Figure 3 shows a generalized block diagram of the information and analytical system for assessing the level of danger and forecasting the risk of emergencies in the Republic of Kazakhstan.

A number of tasks should be solved to achieve the set goal, such as:

- assessment of the risk level of accidents and determination of hazard rates and risk of a possible accident at industrial sites (Risk of Possible Accident computing module);

- assessment of the risk level of industrial traumatism and determination of traumatism risk rates for industrial sites (Risk of Industrial Traumatism computing module);

- assessment of the risk level of occupational diseases among workers and determination of the rate of insalubrity of labour conditions at industrial sites (Labour Conditions computing module);

- detailed analysis and assessment of the state of risk of possible accidents, industrial traumatism and labour condition insalubrity, both for separate production units, and for the entire industrial enterprise as a whole.

The computing module Risk of Possible Accident allows users to determine the risk of possible accidents at the industrial site and to establish its hazard class (by accident risk). This module is characterized by a cluster structure, which allows replacing the types of accidents depending on the type of industry.
Figures 4 and 5 , as an example, demonstrate pages with the output information about the industrial enterprise separated by years, with separate units informing positions of a risk assessment of a possible accident.

The Risk of Industrial Traumatism computing module allows users to analyse the frequency of occupational traumas and their severity, assess the level of occupational trauma risk, and establish the rate and degree of traumatism hazard at industrial sites (Figure 6.

The Labour Conditions computing module (Figure 7) allows users to assess the labour conditions of the industrial site, as well as their varying degrees of insalubrity.

The rate of labour conditions of the industrial unit, and the enterprise as a whole, is determined by the degree of insalubrity as a result of assessment.

The data obtained in each module are transferred into the module of analysis and assessment of hazard levels (Figure 8), where their comprehensive and comparative analysis and assessment are performed. They are compared with previous reporting periods (separated by month, quarter, and year), that allows users to see the dynamics of the hazard change over time. In addition, this module forms an analytical report on the state of industrial and occupational safety, both at the industrial unit level and through seeing the enterprise as a whole. This, in turn, contains data on the overall hazard level of the industrial site, its rates and the degree of risks of possible accidents and industrial traumas as well as the insalubrity of labour conditions.

\section{Conclusion}

The Information and Analytical System allows users to implement a comprehensive approach to the assessment, control, and forecasting of the state of industrial and occupational safety at industrial enterprises of the Republic of Kazakhstan.

The developed Information and Analytical System allows users to calculate quantitative and qualitative indicators of the state of the accident rate and safety engineering for a risk management at hazardous industrial enterprises and sites.

The Information and Analytical System presented by the authors will significantly strengthen the functionality of the CICS SSPLE's Supervisory Activity subsystem.

Due to the Information Monitoring System of the Risk Level, the subsystem "Supervisory activities" of the CICS SSPLE is a united and unified tool for the registration of documents and facilities for supervision, and for the planning of supervisory activities in the field of emergencies.

The introduction of the computer monitoring system in the specialized services of the Emergency Management Committee and the Ministry of Investment and Development of the Republic of Kazakhstan and at industrial enterprises will allow users to analyse the 


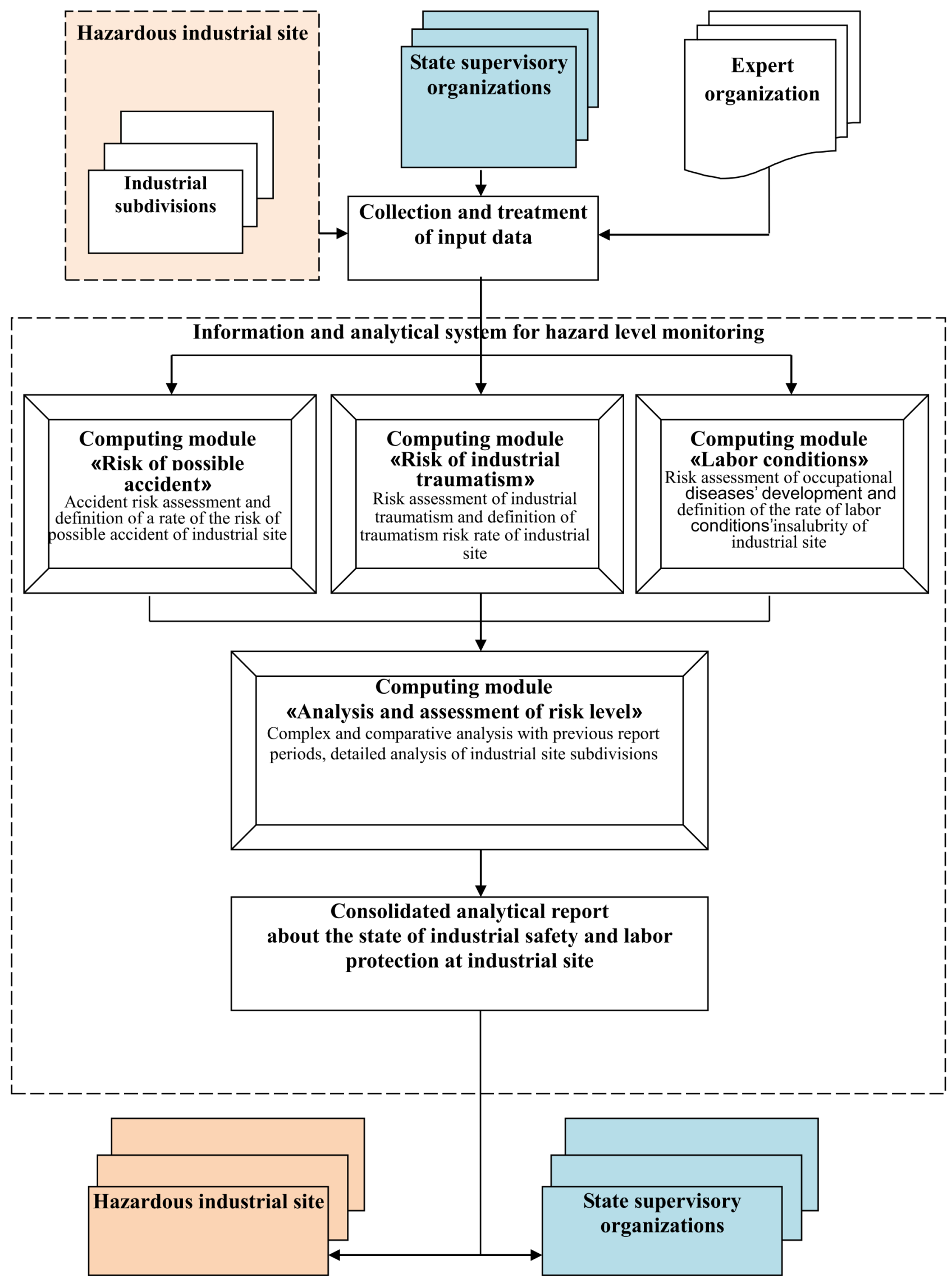

FIGURE 3. Block diagram of the information and analytical system of the hazard level monitoring at hazardous industrial site. 


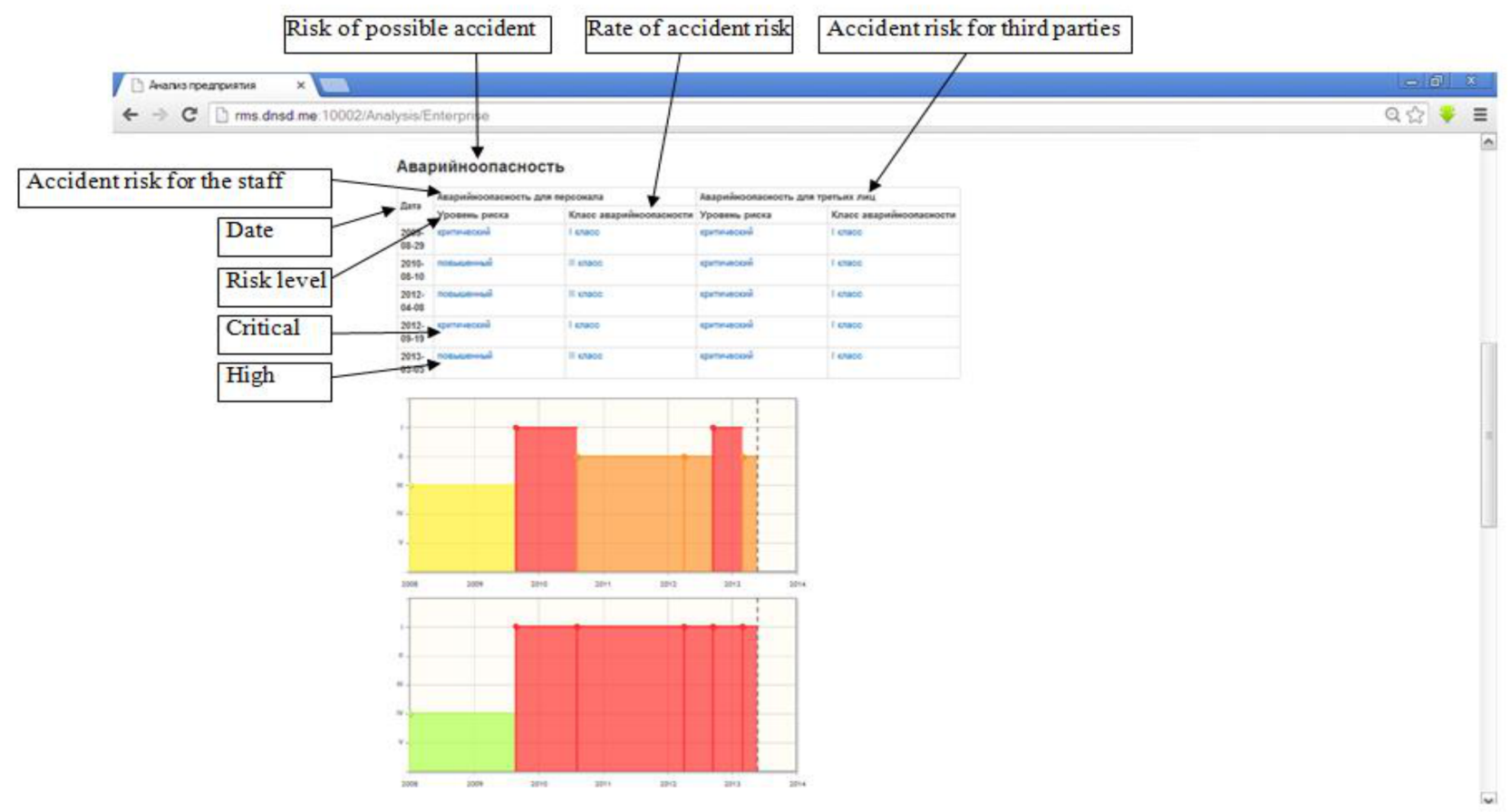

FiguRE 4. Subsystem of analysis and hazard level assessment. Analysis of an enterprise. Risk of possible accidents.

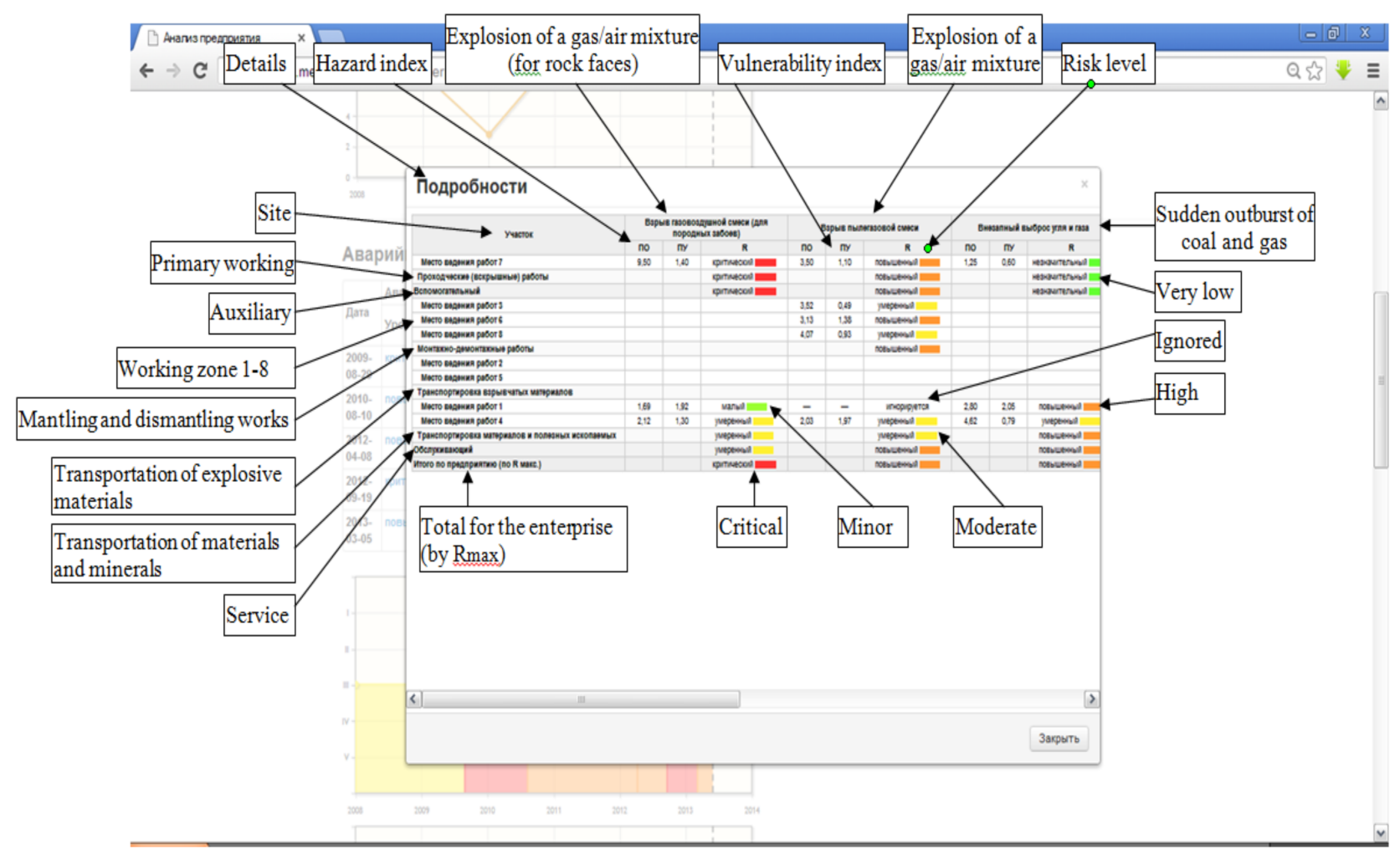

FIgURE 5. Subsystem of hazard levels analysis and assessment. Analysis of an enterprise. Risk of possible accidents. Detailed information. 


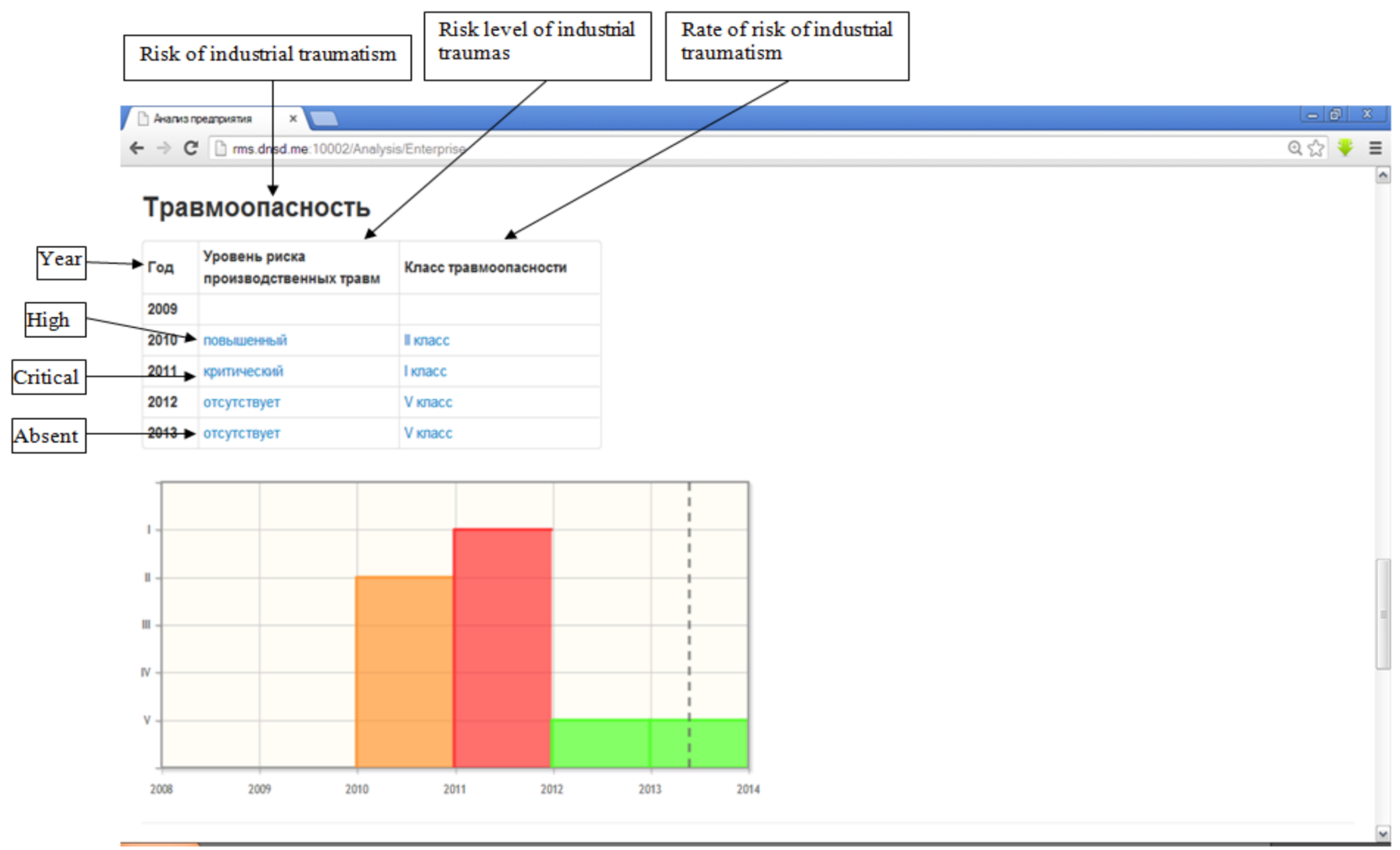

Figure 6. Subsystem of analysis and hazard level assessment. Analysis of an enterprise. Risk of industrial traumatism.

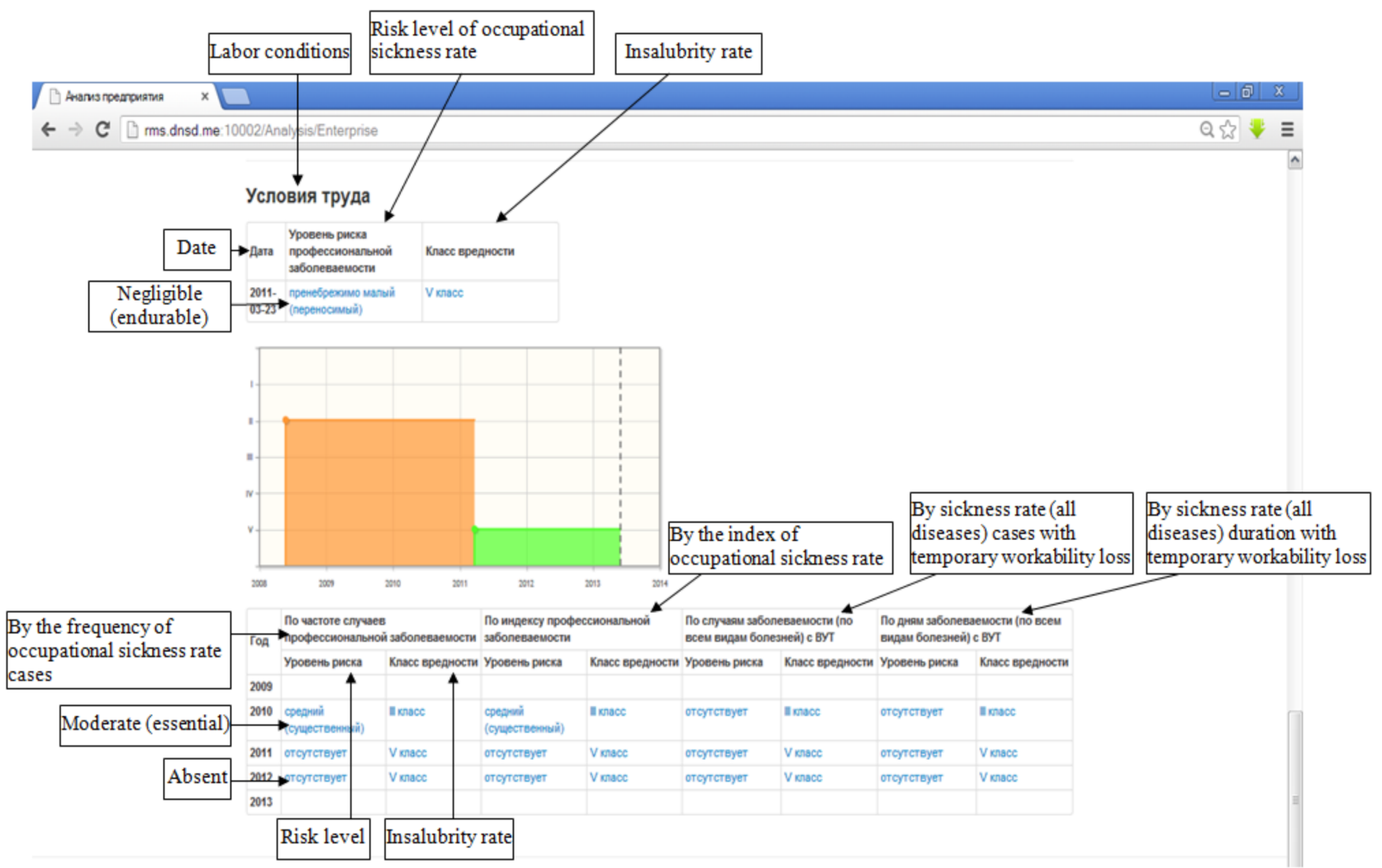

Figure 7. Subsystem of analysis and hazard level assessment. Analysis of an enterprise. Labour conditions. 


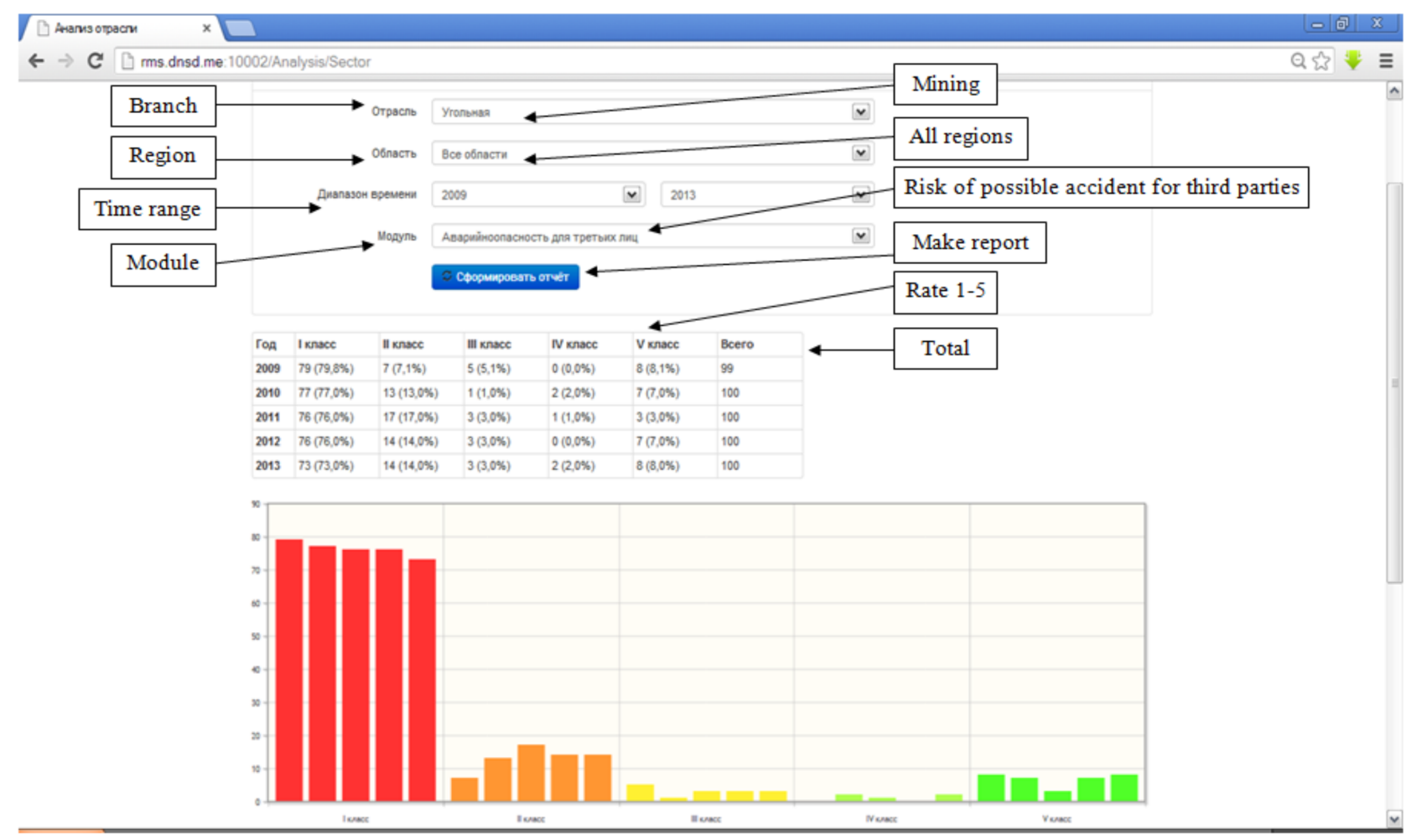

FiguRE 8. Subsystem of hazard levels analysis and assessment. Branch analysis. Risk of possible accidents.

state of accidents, occupational traumas and disease rates constantly and objectively; as a consequence, the implementation will go a long way towards comprehensively approaching the task of increasing the level of industrial and occupational safety at industrial sites in the Republic of Kazakhstan.

\section{ACKNOWLEDGEMENTS}

This work was supported by the Ministry of Education and Science of the Republic of Kazakhstan under Grant AP 05133965. The authors would like to thank English Language Fellow Ben Taylor for his assistance with the preparation of this article. The authors would like to thank the editors and anonymous reviewers for their insightful comments and suggestions.

There are not any potential conflicts of interest that could influence the authors' interpretation of the data

\section{REFERENCES}

[1] ISO 31000:2009 - Risk management - Principles and guidelines. Standard, International Standard Organization, Geneva, 2009.

[2] National Standard of Russian Federation 12.0.010-2009 - Occupational Safety Standards System Occupational Safety and Health Management Systems Hazard and Risks Identification and Estimation of Risks. Standard, Standartinform, Moscow, 2011.

[3] Standard of the Republic of Kazakhstan IEC 61025:1991, IDT - Risk Management - Fault Tree Analysis. Standard, National Standard of the Republic of Kazakhstan, Astana, 2005.

[4] Standard of the Republic of Kazakhstan IEC 61078-2005 (IEC 61078:1991, IDT) - Risk Management -
Analysis Methods Based on Reliability Flow Diagram. Standard, National Standard of the Republic of Kazakhstan, Astana, 2005.

[5] Standard of the Republic of Kazakhstan 31010-ISO/IEC: 31010-2009, IDT - Risk Management Risk Assessment Techniques. Standard, National Standard of the Republic of Kazakhstan, Astana, 2010.

[6] Standard of the Republic of Kazakhstan 1.56-2005 (60300-3-9:1995, MOD) - Risk Management - System of Dependability Management - Risk Analysis of Technological Systems. Standard, National Standard of the Republic of Kazakhstan, Astana, 2005.

[7] Standard of the Republic of Kazakhstan ISO 73-2010 Risk Management. Standard, National Standard of the Republic of Kazakhstan, Astana, 2011.

[8] S. S. Kudryavtsev, P. V. Yemelin, N. K. Yemelina. The development of a risk management system in the field of industrial safety in the Republic of Kazakhstan. Safety and Health at Work 9(1):30-41, 2018. DOI:10.1016/j.shaw.2017.06.003

[9] S. Amurgalinov, P. Yemelin, G. Sattarova. Potential hazards of mining enterprises. Promyshlennost' Kazakhstana 10:29-32, 2012.

[10] E. G. Davydov, et al. Assessment of human factor impact on the appearance of technogenic accidents in coal mines. In Proceedings of the 1-st Scientific and Practical Conference Actual issues of prevention and liquidation of consequences of man-made emergencies, pp. 135-137. Kazakh Research Institute of Works' Safety in Mining Industry, Karaganda, 2010.

[11] B. Z. Hamimolda, P. V. Yemelin, G. S. Sattarova. The development of the multifactorial models' structure for risk assessment of accidents at the enterprises of 
mining field of the Republic of Kazakhstan. In Proceedings of the 2-nd Scientific and Practical Conference Prevention of man-made accidents caused by changes in the geomechanical state of the massif in the process of developing mineral deposits in the Republic of Kazakhstan, p. 66. Kazakh Research Institute of Works' Safety in Mining Industry, Karaganda, 2011.

[12] B. Z. Hamimolda, et al. Methodical approach to assess risk of accidents at mining enterprises. In Proceedings of the International Scientific and Practical Conference Mining and metallurgical complex of Kazakhstan: Problems and perspectives of innovative development, pp. 78-81. Karaganda State Technical University, Karaganda, 2011.

[13] B. Z. Hamimolda, P. V. Yemelin, G. S. Sattarova. Analysis of hazard's sources and risk assessment of the appearance of accidents at mining enterprises. Okhrana Truda, Kazakhstan 3:81-86, 2012.

[14] S. S. Kudryavtsev, et al. Analysis of industrial accidents causes at mines of karaganda coal basin. Trudy Universiteta 4:55-60, 2015.

[15] S. S. Kudryavtsev, et al. Analysis of industrial traumatism causes at underground mines in Karaganda region. Trudy Universiteta 1:113-116, 2017.

[16] S. S. Kudryavtsev. Condition of professional sickness rate of workers of mines in the Republic of Kazakhstan. In Proceedings of the 3-rd Scientific and Practical Conference Actual issues of prevention and liquidation of consequences of man-made emergencies, pp. 109-111. Karaganda Research Institute of Industrial Safety, Karaganda, 2013.
[17] S. S. Kudryavtsev, O. Kostogladova. Kudryavtsev, s. s., kostogladova, o.l.: Condition of occupational sickness rate of workers of the mining industry. Okhrana Truda, Kazakhstan 3:89-92, 2013.

[18] S. S. Kudryavtsev, et al. Condition of professional incidence of pit workers in the Republic of Kazakhstan. Trudy Universiteta 4:102-104, 2016.

[19] P. V. Yemelin, G. S. Sattarova, S. S. Kudryavtsev. Occupational sickness rate of workers of mines of Karaganda coal basin. In Proceedings of the 2-nd Scientific and Practical Conference Prevention of man-made accidents caused by changes in the geomechanical state of the massif in the process of developing mineral deposits in the Republic of Kazakhstan, p. 80. Kazakh Research Institute of Works' Safety in Mining Industry, Karaganda, 2011.

[20] S. S. Kudryavtsev, G. S. Sattarova, S. S. Sattarov. Hazard analysis and accidents' risk assessment at the objects of Nurkazgan industrial complex. In Proceedings of the International Scientific and Practical Conference Integration of science, education and industry is the basis for implementing the Plan of the Nation, pp. 163-166. Karaganda State Technical University, Karaganda, 2015. 